\title{
Oral health status of asthmatic children using inhaled corticosteroids
}

\author{
Münevver Doğan ${ }^{1 \oplus}$, Ümit Murat Şahiner $^{2 \oplus}$, Atilla Stephan Ataç ${ }^{1 \oplus}$, Elif Ballıkaya ${ }^{1 \oplus}$, \\ Özge Uysal Soyer ${ }^{2}$, , Bülent Enis Şekerel2 ${ }^{2 \oplus}$
}

${ }^{1}$ Department of Pediatric Dentistry, Hacettepe University Faculty of Dentistry, ${ }^{2}$ Department of Pediatric Allergy, Hacettepe University Faculty of Medicine, Ankara, Turkey.

\begin{abstract}
Background. Due to the increase in the prevalence of asthma, especially in childhood, oral health problems arising from the use of asthma medications have become a major health concern. Inhaled corticosteroids are widely used since they are the cornerstone of asthma management. This study aimed to investigate the effects of inhaled corticosteroids on oral health and various factors regarding active ingredients in inhalers, inhaler-spacer device use, rinsing the mouth after administration of inhaler, oral hygiene practices and parents' education on dental caries susceptibility in young children with asthma.
\end{abstract}

Methods. Children with asthma who were treated with inhaled corticosteroids for at least 6 months were included in the study. A questionnaire related to demographic characteristics and oral health practices of children was conducted with parents and the children were examined using a dental mirror and probe under dental unit lighting after air-drying the teeth.

Results. Oral health status was evaluated in 115 children, 54 (42-66) months old, $61 \%$ male and 39\% female with determination of dmft-dmfs, DMFT-DMFS, ICDAS II, plaque index and gingival index. No statistically significant difference was found between sugar-containing and sugar-free inhalers, duration of inhaled corticosteroid use, inhaler-spacer device use, rinsing the mouth after administration of inhaler and dmft-dmfs, DMFT-DMFS, plaque and gingival index $(\mathrm{p}>0.05)$. Long-term inhaled corticosteroid use was significantly associated with oral candidiasis $(\mathrm{p}=0.029)$. Also, the results showed that mothers' educational level had a significant effect on children's oral health $\left(\mathrm{p}_{\text {dmft/dmfs }}<0.001 ; \mathrm{p}_{\text {gingival index }}=0.049 ; \mathrm{p}_{\text {plaque index }}=0.005\right)$.

Conclusion. Due to the effect of immunosuppression, long-term use of inhaled corticosteroids enhances the risk of development of the opportunistic pathogen candida. Regular dental visits and preventive dental treatments are needed in these patients for healthy oral status.

Key words: asthma, children, inhalers, corticosteroid, oral health.

Asthma is a chronic inflammatory disorder of the airways characterized by hyper-responsiveness and episodic, reversible symptoms of airflow obstruction, either spontaneously or with treatment. It is a serious health problem throughout the world. Asthma has a higher incidence among preschool children. ${ }^{1}$

ه Münevver Doğan

sener.munevver@gmail.com

Received 3rd February 2020, revised 5th June 2020, accepted 10th June 2020.

This study was presented at 23rd National Congress of Allergy and Clinical Immunology, 2016, Muğla, Turkey.
Inhaled corticosteroids, through their antiinflammatory effects have been the cornerstone of asthma management for decades. However, use of inhaled corticosteroids creates concerns due to fear of systemic side effects such as suppression of adrenal axis and longitudinal growth, or decrease in bone mineral density. The administration route of these drugs is inhalation so they act directly on airways, nevertheless this may lead to local adverse effects regarding oral health. The association of asthma with oral health status such as dental caries, periodontal disease, dental erosion and 
oral mucosal changes have been the subject of discussion among dental practitioners. ${ }^{2}$ Asthma medications, especially inhalers, may cause mouth dryness, which makes the person vulnerable to caries and predisposes the child to fungal infections. Epidemiological studies investigating the effect of asthma on dental caries are conflicting. The majority of the studies conclude that asthmatic children have higher dental caries prevalence, whereas some oppose such conclusions. ${ }^{3-6}$ The increased susceptibility to dental caries may also be due to the antiasthmatic medications containing fermentable carbohydrates. The most common is lactose monohydrate, and although it is one of the least cariogenic sugars, this still can lead to increased dental caries risk. ${ }^{7}$

Studies assessing the periodontal status of children with asthma have revealed different results. ${ }^{3,4,8}$ Corticosteroids are thought to play an important role in the development of candida infection owing to immunosuppression. ${ }^{9}$

In this study, we aimed to evaluate the oral health of young children with asthma and also possible effects of some variables on oral health such as type of inhaled corticosteroids, inhaler-spacer device use, rinsing the mouth after administration of inhaler, sex, oral hygiene practices and parents' education.

\section{Material and Methods}

Institutional Hacettepe University Ethics Committee approved the study (2016, GO 16/108-08) and written informed consent was obtained from parents. 115 children with asthma, 54 (42-66) months old, 61\% male and $39 \%$ female who were admitted to Hacettepe University, Department of Pediatric Allergy and treated with inhaled corticosteroids for at least 6 months were included in the study. The exclusion criterion was the presence of any systemic illness other than asthma.

After a face to face questionnaire covering demographic data including age, sex, education level of parents, medical and dental history, oral health habits, and complaints of participants related to oral health (halitosis, toothache, etc.) were completed by the parents, all of the children wereexamined by the same pediatric dentist with a dental mirror and ball-ended explorer (WHO 973/80-Martin, Solingen, Germany) according to World Health Organization (WHO) criteria. ${ }^{10}$ The dental caries diagnosis was checked for intra-examiner agreement by employing two separate evaluations in 10 children with 1-week interval between examinations. (Kappa score for ICDAS II = 0.88). The caries status was diagnosed according to $\mathrm{dmft} / \mathrm{dmfs}-\mathrm{DMFT} /$ DMFS indices in which decayed (D/d), missing $(\mathrm{M} / \mathrm{m})$ and filled $(\mathrm{F} / \mathrm{f})$ teeth are appraised and reported according to number of teeth (DMFT/ $\mathrm{dmft}$ ) or surfaces (DMFS/dmfs) involved with codes and criteria determined by WHO. ${ }^{10}$ Total number of decayed, missing and filled deciduous teeth were recorded as children's $\mathrm{dmft} / \mathrm{dmfs}$; permanent teeth were recorded as children's DMFT/DMFS. This index is the most commonly used index in research because of its advantages including being simple, easy to apply and being statistically useful. However, in this scale, obvious cavity lesions extending into the dentine have been scored. In addition, diagnosis of dental caries was performed according to International Caries Detection and Assessment System-II (ICDAS II) index which was improved to include early enamel caries lesions. Stage of lesions were also used by means of visual/tactile examination without radiographs. ${ }^{11}$

The gingival health and the amount of plaque were assessed using the plaque and gingival index of Silness and Löe. ${ }^{12,13}$ The grade of plaque evaluation was performed in four regions (mesial, distal, lingual, labial) for each tooth. The plaque accumulation was evaluated and coded as follows:

0- No plaque

1- A film of plaque adhering to the free gingival margin and adjacent area of the tooth, which cannot be seen by the naked eye, but only by using a disclosing solution or by using a probe. 
2- Moderate accumulation of deposits within the gingival pocket, on the gingival margin and/or adjacent tooth surface, which can be seen by the naked eye.

3- Abundance of soft matter within the gingival pocket and/or on the tooth and gingival margin.

Scores for each surface were added and divided by the total number of surfaces of examined teeth in order to obtain the individual plaque score. The mean plaque index was classified as follows: no $<0.1$, minimal $0.1-1.0$, moderate 1.1-2.0, and heavy 2.1-3.0. The gingival health status was determined similar to plaque index on four regions (mesial, distal, lingual, labial). The ball-ended explorer was slightly inserted into the gingival pocket between gingiva and teeth with a probing force not exceeding $20 \mathrm{~g} .{ }^{10}$ The gingival health was evaluated and coded as follows:

\section{0- Normal gingiva: No inflammation}

1- Mild inflammation: Slight changes in color, slight edema. No bleeding on probing.

2- Moderate inflammation: Redness, edema and glazing. Bleeding upon probing.

3- Severe inflammation: Marked redness and edema/ulceration/tendency to bleed spontaneously.

The individual gingival score was calculated as the plaque score. Finally, the mean score for each index was calculated by adding the individual scores and dividing by the total number of patients.

Also, the soft tissues including the tongue were examined intraorally and the differences were registered. The control levels of asthma were categorized as 'well-controlled', 'partly controlled' and 'uncontrolled' based on symptom frequency and reliever medication need within the last 4 weeks according to the Global Initiative for Asthma (GINA). ${ }^{14}$ The children were grouped by the active ingredient of inhaled corticosteroids (fluticasone propionate and budesonide+lactose) that they used. The status of oral thrush development, which shows candida infection, during or immediately after inhaler use was questioned to the parents. The oral health indices in deciduous dentition and permanent teeth were compared by the parental education level.

The results were analyzed with SPSS 22.0 (SPSS, Inc, Chicago, IL, USA). Number, percentage, mean, standard deviation, median, 1st and 3rd quartiles, minimum and maximum values were estimated for descriptive statistics. Shapiro-Wilk test, tested the normality of the distributions; Mann Whitney-U test was used for comparing two independent groups. Chisquare was used to assess the significance of the differences between categorical variables. The significance level was considered as 0.05 in all analyses.

\section{Results}

115 children 54 (42-66) months old, 61\% male and $39 \%$ female were involved in the study. The children's major complaints were halitosis, dental caries, oral candidiasis and toothache. According to parental report, mouth breathing was present in one-third of children $(n=40)$. The frequency of brushing teeth was determined as less than once a day (54.8\%), once a day $(17.4 \%)$, twice a day $(16.5 \%)$, three times a day $(0.9 \%)$ and $10.4 \%$ of children did not brush their teeth. More than half of the children (67\%) had not visited a dentist previously

The duration of use of inhaled corticosteroids was $24.0(12-24)$ [median ( $1^{\text {st }}$ and $3^{\text {rd }}$ quartiles] months. Asthma levels of the children were well controlled (53.9\%), partly controlled $(26.9 \%)$ and uncontrolled (19.2\%). The children had been using Flixotide propionate $(74.8 \%)$ and budesonide+lactose (25.2\%) (Table I).

Among parents; $33.0 \%$ of the mothers, $26.1 \%$ of the fathers had graduated from high school and $27.8 \%$ of the mothers, $29.6 \%$ of fathers had graduated from university. The remaining parents were educated until secondary school. 
Table I. Characteristics of patients according to self-reports of parents (Ankara-Turkey, 2016).

\begin{tabular}{|c|c|c|}
\hline Characteristics $(\mathrm{n}=115)$ & & \\
\hline Age [median(interquartile range)] & & \\
\hline Sex & $\mathrm{n}$ & $\%$ \\
\hline Male & 70 & 61 \\
\hline Female & 45 & 39 \\
\hline Frequency of tooth brushing & $\mathrm{n}$ & $\%$ \\
\hline No brushing & 12 & 10.4 \\
\hline Less than once/day & 63 & 54.8 \\
\hline Once/day & 20 & 17.4 \\
\hline Twice/day & 19 & 16.5 \\
\hline 3 times/day & 1 & 0.9 \\
\hline Complaints related to oral health $\mathrm{n}$ & $\mathrm{n}$ & $\%$ \\
\hline Yes & 85 & 73.9 \\
\hline Halitosis* & 53 & 62.4 \\
\hline Dental caries ${ }^{*}$ & 42 & 49.4 \\
\hline Oral candidiasis* & 32 & 37.6 \\
\hline Toothache* & 24 & 28.2 \\
\hline Previous dental visits & $\mathrm{n}$ & $\%$ \\
\hline No & 77 & 67 \\
\hline Yes & 38 & 33 \\
\hline Asthma control level & $\mathrm{n}$ & $\%$ \\
\hline Well controlled & 62 & 53.9 \\
\hline Partly controlled & 31 & 26.9 \\
\hline Uncontrolled & 22 & 19.2 \\
\hline Type of inhaler & $\mathrm{n}$ & $\%$ \\
\hline Flixotide propionate & 86 & 74.8 \\
\hline Budesonide+lactose & 29 & 25.2 \\
\hline
\end{tabular}

There is more than one answer; the percentages calculated over the 85 patients reporting any complaint.

The patients who had experienced oral candidiasis had a significantly longer duration of inhaled corticosteroid use compared to the ones who had not experienced oral candidiasis $(p=0.029)$ (Table II). With regard to oral care habits (children with no brushing \& less than once a day or brushing) compared to oral candidiasis; the complaint of oral candidiasis was less in children who brushed their teeth regularly $(n=13,40.6 \%)$ but this difference was not statistically significant $(\mathrm{p}>0.05)$.

The mean dmf/DMF scores for teeth and surfaces were $\mathrm{dmft}=2.69 \pm 3.58, \mathrm{dmfs}=4.97 \pm 8.27$, $\mathrm{DMFT}=0.28 \pm 0.58$ and DMFS $=0.28 \pm 0.58$ (Table III). It was found that $58.3 \%$ of the children had shown tooth decay on their primary and/ or permanent teeth by visual inspection. The mean plaque indices were $0.69 \pm 0.43$ and gingival indices were $0.24 \pm 0.27$ for the whole study group (Table III). The reported gingival inflammation was mild in $70.4 \%$ and moderate in $2.6 \%$ of the study group. In addition, $27 \%$ of the study group had no gingival inflammation. 8 of 115 children had a geographic tongue appearance.

In the intraoral examination, all the children's existing teeth were given codes according to the ICDAS II index, and the highest individual ICDAS codes taken were recorded (Table IV). It was determined that $4.3 \%$ of the whole children 
Table II. Duration of inhaled corticosteroid use by patients with complaint of oral candidiasis (Ankara-Turkey, 2016).

\begin{tabular}{|c|c|c|c|c|}
\hline & \multicolumn{2}{|c|}{ Oral candidiasis } & \multirow{3}{*}{$\mathrm{z}$} & \multirow{3}{*}{$\mathrm{p}^{*}$} \\
\hline & Yes & No & & \\
\hline & Median (Min-Max) & Median (Min-Max) & & \\
\hline Duration of inhaled corticosteroid use (month) & $24(6-72)$ & $16(6-60)$ & -2.186 & 0.029 \\
\hline
\end{tabular}

Table III. Distributions of dmft(S)/DMFT(S), gingival and plaque indices scores (Ankara-Turkey, 2016).

\begin{tabular}{lcccccc}
\hline Distributions & $\begin{array}{c}\mathrm{dmft}^{*} \\
(\mathrm{n}=115)\end{array}$ & $\begin{array}{c}\mathrm{dmfs}^{*} \\
(\mathrm{n}=115)\end{array}$ & $\begin{array}{c}\mathrm{DMFT}^{*} \\
(\mathrm{n}=18)^{* *}\end{array}$ & $\begin{array}{c}\mathrm{DMFS}^{*} \\
(\mathrm{n}=18)^{* *}\end{array}$ & $\begin{array}{c}\text { Plaque index } \\
(\mathrm{n}=115)\end{array}$ & $\begin{array}{c}\text { Gingival index } \\
(\mathrm{n}=115)\end{array}$ \\
\hline $\mathrm{X} \pm \mathrm{SD}$ & $2.69 \pm 3.58$ & $4.97 \pm 8.27$ & $0.28 \pm 0.58$ & $0.28 \pm 0.58$ & $0.69 \pm 0.43$ & $0.24 \pm 0.27$ \\
Median & 1.0 & 1.0 & 0.0 & 0.0 & 0.57 & 0.18 \\
1.Quartile & 0.0 & 0.0 & 0.0 & 0.0 & 0.32 & 0.07 \\
3.Quartile & 4.0 & 6.0 & 0.25 & 0.25 & 0.96 & 0.33 \\
Min-Max & $0-15$ & $0-43$ & $0-2$ & $0-2$ & $0.0-2.01$ & $0.0-2.0$ \\
\hline
\end{tabular}

*Total number of decayed, missing and filled teeth (DMFT/ dmft) and surfaces (DMFS/dmfs) were recorded. Dmft/s for primary teeth, DMFT/S codes for permanent teeth are involved in.

${ }^{* *}$ DMFT/DMFS values could only be evaluated in 18 patients due to mixed dentition.

Table IV. International caries detection and assessment system-II (ICDAS II) scoring criteria. ${ }^{11}$

\begin{tabular}{|c|c|}
\hline Score & Clinical criteria description \\
\hline 0 & $\begin{array}{l}\text { Sound tooth: no evidence of caries after prolonged air-drying ( } 5 \mathrm{~s}) \text {, surfaces with developmental } \\
\text { defects (enamel hypoplasia, fluorosis), tooth wear (attrition, abrasion and erosion), and extrinsic or } \\
\text { intrinsic stains will be recorded as sound. }\end{array}$ \\
\hline 1 & $\begin{array}{l}\text { First visual change in enamel: opacity or discoloration is visible after prolonged air-drying, which is } \\
\text { not or hardly seen on a wet surface. }\end{array}$ \\
\hline 2 & $\begin{array}{l}\text { Distinct visual change in enamel: opacity or discoloration distinctly visible when wet, lesion must still } \\
\text { be visible when dry. }\end{array}$ \\
\hline 3 & Localized enamel breakdown owing to caries with no visible dentin or underlying shadow. \\
\hline 4 & Underlying dark shadow from dentin with or without localized enamel breakdown. \\
\hline 5 & Distinct cavity with visible dentin: visual evidence of demineralization and dentin exposed. \\
\hline 6 & $\begin{array}{l}\text { Extensive distinct cavity with visible dentin with more than half of the tooth surface involved or } \\
\text { possibly reaching the pulp. }\end{array}$ \\
\hline
\end{tabular}

in the study had completely healthy teeth, $31.3 \%$ had initial caries (ICDAS=1 or 2 ), $6.1 \%$ had moderate (ICDAS=3 or 4 ), and $58.2 \%$ had advanced caries (ICDAS $=5$ or 6 ). There was no significant difference by sex $(\mathrm{p}=0.394)$ (Table V).

No significant differences were found in terms of dental caries, plaque indices, gingival indices and inhaler content between sugar-containing (budesonide+lactose) and sugar-free (flixotide propionate) inhaler groups.
The score of caries in deciduous dentition, gingival and plaque indices were significantly lower in children of mothers with high education level. $\quad\left(\mathrm{p}_{\mathrm{dmft} / \mathrm{dmfs}}<0.001 ; \quad \mathrm{p}_{\text {gingival }}\right.$ index $\left.=0.049 ; p_{\text {plaque index }}=0.005\right)$. The score of caries in permanent teeth was lower in children of mothers with high education level, but this difference was not statistically significant. No statistically significant difference was found when comparing the education levels of the fathers. 
Table V. Distribution of ICDAS II codes classification by sex (Ankara-Turkey, 2016).

\begin{tabular}{|c|c|c|c|c|c|}
\hline \multirow{3}{*}{$\begin{array}{l}\text { ICDAS } \\
\text { Codes }\end{array}$} & \multicolumn{4}{|c|}{ Sex } & \multirow[b]{3}{*}{$P^{* *}$} \\
\hline & \multicolumn{2}{|c|}{ Female } & \multicolumn{2}{|c|}{ Male } & \\
\hline & $\mathrm{n}$ & $\% *$ & $\mathrm{n}$ & $\% *$ & \\
\hline 0 (sound) & 2 & 4.4 & 3 & 4.3 & \multirow{4}{*}{0.394} \\
\hline 1-2 (initial) & 18 & 40.0 & 18 & 25.7 & \\
\hline 3-4 (moderate) & 3 & 6.7 & 4 & 5.7 & \\
\hline 5-6 (severe) & 22 & 48.9 & 45 & 64.3 & \\
\hline Total & 45 & 100 & 70 & 100 & \\
\hline
\end{tabular}

*Column percentage

** $p>0.05$

No significant differences were found between oral health outcome variables (dmft/dmfs, DFT/ DMFS, gingival and plaque indices) and asthma control levels (well-controlled, partly controlled and uncontrolled) ( $\mathrm{p}>0.005)$.

In this study, the mean duration of inhaled corticosteroid use in 115 asthmatic children was $19.84 \pm 11.46$ months. As the duration of inhaled corticosteroid use prolonged, $\mathrm{dmft} /$ $\mathrm{dmfs}$ and DMFT/DMFS scores, gingival and plaque indices were found to increase. But we did not find a statistically significant association between duration of inhaled corticosteroid use, inhaler-spacer device use, rinsing the mouth after administration of inhaler and dmft-dmfs, DMFT-DMFS, plaque and gingival index $(\mathrm{p}>0.05)$.

\section{Discussion}

Asthma and dental caries are the most common chronic diseases of childhood and two major causes of school absenteeism. ${ }^{15,16}$ Studies regarding dental caries in the primary and permanent dentition, oral hygiene and diet, duration of asthmatic symptoms, exposure time to medication and severity of asthma, the association between asthma and caries have been prominent issues in the literature. Further studies are required due to inconsistent consequences and there is no study regarding the severity of dental caries in asthmatic children as far as we know. In the present study, dental caries were assessed according to WHO criteria and recorded according to the DMFT/DMFS, $\mathrm{dmft} / \mathrm{dmfs}$ index and ICDAS II index. Although oral health status in children with asthma have been reported in some studies, there is no study, which evaluated the severity of caries. The ICDAS index system allows the evaluation of initial caries and has codes according to the stages of caries. ${ }^{11,17}$ DMF index, has been used worldwide in dental research but is unable to provide accurate data about initial lesions and severity of lesions.

In previous studies, researchers usually have studied case-control groups consisting of healthy and asthmatic children. It was reported that healthy children had higher DMFT scores than asthmatics. ${ }^{5,6}$ Shulman $^{18}$ and Meldrum ${ }^{19}$ found no association between dental caries and asthma. Mazzoleni et al. ${ }^{20}$ noted that DMFT scores were statistically significantly higher in asthmatic children, but there was no significant difference in $\mathrm{dmft}$ scores between groups. Stensson et al. ${ }^{3}$ reported that $29 \%$ of 3 -yearold children and $49 \%$ of 6-year-old children with asthma had dental caries and preschool children with asthma have higher caries prevalence than healthy children. The factors discriminating for caries in asthmatic children had been considered as higher intake of sugary drinks, mouth breathing, and immigrant background. In the present study, 67 (58.3\%) of the children had shown caries in terms of $\mathrm{dmf}$ index. However, according to the ICDAS II index, only 5 (4.3\%) had healthy teeth, 36 $(31.3 \%)$ had initial, 7 (6.1\%) had moderate and 67 (58.2\%) had advanced caries lesions. Regarding 
the severity of caries, similar to this study, no healthy children were present in a study conducted on 150 children with adenotonsillar hypertrophy in which mouth breathing and dry mouth are also common predisposing factors to caries in asthmatic children. ${ }^{21}$ The differences in the dental caries prevalence might be sourced from the concomitant factors aggravating dental caries as diet, hygiene, the severity of caries, and mouth breathing.

The results in the present study showed that mothers' educational level had a significant effect on the oral health of children with deciduous dentition but the fathers' educational level had no significant effect. Khalilzadeh et al. ${ }^{22}$ reported that the DMFT scores of children with high economic income and high education level of their mothers were lower. In another study, it was reported that individuals with high socioeconomic status had better oral health than those with low socioeconomic status. ${ }^{23}$

McDerra et al. ${ }^{24}$ reported that the presence of calculus, gingival inflammation and dental plaque in asthmatic children was significantly higher than the control group. Laurikainen et al. ${ }^{25}$ noticed that asthmatic children had higher periodontal disease and lower salivary flow rate. Studies showed that more dental calculus was seen in asthmatic patients due to increased calcium and phosphate in the saliva. The children in these studies were older than the present study. There are a few studies in preschool children with asthma. Stensson et al. $^{3}$ reported gingivitis in $14.9 \%$ of preschool children with asthma. In present study, only $2.6 \%$ of the children had moderate gingival inflammation showing bleeding by probing and dense calculus accumulation was seen in only 1 patient. Differences in oral care habits, mouth breathing prevalence, the consumption of sugar-containing drinks and the period of medication exposure of children could be the reason for these variations in studies.

Ersin et $a .^{26}$ found that the duration of drug use and the severity of asthma increased the risk of caries development. The increased caries prevalence according to the severity of asthma may be due to increased dosage and frequency of medications used in asthma treatment. ${ }^{27}$ Milano at al. ${ }^{28}$ reported that duration of use and frequency of medications used in asthma treatment were associated with increased dental caries, and deciduous dentition was more affected. The duration of inhaled corticosteroid use was higher in asthmatic children with dental caries in present study, but this difference was not statistically significant. Eloot et al. ${ }^{4}$ examined the effects of asthma severity and duration of drug use on caries prevalence, gingival and plaque indices and found no statistically significant differences. The results of this study are consistent with the results obtained in our study.

Tootla et al. ${ }^{7}$ showed that inhaled corticosteroids caused a significant decrease in plaque $\mathrm{pH}$. The study of Shashikiran et al. ${ }^{15}$ was conducted with 105, six to fourteen-year-old asthmatic children to determine the condition of their dental caries and their periodontal status before and after taking anti-asthmatic medication, for a period of 1 year and these were matched with their controls. The results showed that the salbutamol inhaler had an increased caries rate with high significance over other groups, which was followed by salbutamol tablets and the beclomethasone inhaler, respectively. In the group using an inhaler with beclomethasone, there was an increase in the caries rate compared to healthy individuals, but this was not statistically significant. In our study, patients used sugar-containing and sugar-free inhaled corticosteroids. The salbutamol inhaler was not routinely used, only when asthmatic children had an episode. Therefore, the aim of our study was to determine the effects of inhaled corticosteroids rather than the effects of $\beta 2$-agonist drugs. According to the data obtained from this study, the caries prevalence and gingival indices were not significantly different in the sugar-containing group and the sugar-free group.

Use of the inhaler spacer and rinsing the mouth with water immediately after use of an 
inhaler was described as a protective factor for development of caries but no statistically significant difference was found in our study.

Inhaled corticosteroids constitute the most important group of drugs for bronchial asthma treatment due to anti-inflammatory effects. ${ }^{29}$ Immunosuppression effects of steroids provide a selective growth advantage to the opportunistic pathogen c. albicans. ${ }^{30}$ Knight and Fletcher ${ }^{31}$ reported that patients receiving corticosteroid therapy had higher levels of glucose in their saliva than in the control group. This supports growth, proliferation and adherence of $\mathrm{C}$. albicans to oral mucosa cells. ${ }^{32}$ Kuna et al. ${ }^{33}$ reported that oral candidiasis occurred in 10$30 \%$ of patients using inhaled corticosteroids. Similarly, we also learned that oral candidiasis had developed in 32 (37.6\%) children during the use of inhaled corticosteroids in the present study. In addition, oral candidiasis increased statistically as duration of inhaled corticosteroid usage increased.

In asthmatic patients, the presence of geographic tongue is based on an underlying allergic condition. ${ }^{34}$ In our study 8 of 115 children had a geographic tongue appearance.

According to the results of the present study, the halitosis complaint reported by parents was $62.4 \%$. It was reported in previous studies that halitosis could be seen due to oropharyngeal candidiasis or mouth breathing which are possible symptoms in asthma patients. ${ }^{3,35,36} \mathrm{In}$ this study, mouth breathing or oral candidiasis was present only in one-third of children. The method of determination of halitosis; (in the present study, it was evaluated via a questionnaire completed by parents) or differences in oral care habits and the mouth breathing prevalence of the study groupchildren with asthma could affect the halitosis prevalence. As far as we have reviewed the literature, no study regarding the prevalence of halitosis in asthma children is present. More studies with a high sample size should be conducted to reveal the possible correlations with halitosis in asthmatic children.
The results of this study should be considered in light of its limitations. As this was a nonrepresentative descriptive study of the asthmatic children who were treated with inhaled corticosteroids only, the results cannot be generalized to the whole population. Prospective cohort studies with larger sample sizes including both asthmatic children using inhalers and children without asthma are strongly suggested to fully clarify the mechanism between asthma, inhalers and oral health by performing multivariate analyses like logistic regression.

In conclusion; oral health is an essential part of general bodily health. Poor oral hygiene adversely affects both physical health and quality of life. Patients should be referred to dentists by their physicians before they take inhaled corticosteroids. Oral health can be preserved through a multidisciplinary approach, periodical dental check-ups, close monitoring and preventive management.

\section{REFERENCES}

1. Bateman ED, Hurd SS, Barnes PJ, et al. Global strategy for asthma management and prevention: GINA executive summary. Eur Respir J 2008; 31: 143-178.

2. Steinbacher DM, Glick M. The dental patient with asthma: an update and oral health considerations. J Am Dent Assoc 2001; 132: 1229-1239.

3. Stensson M, Wendt LK, Koch G, Oldaeus G, Birkhed D. Oral health in preschool children with asthma. Int J Paediatr Dent 2008; 18: 243-250.

4. Eloot AK, Vanobbergen JN, De Baets F, Martens LC. Oral health and habits in children with asthma related to severity and duration of condition. Eur J Paediatr Dent 2004; 5: 210-215.

5. Brigic A, Kobaslija S, Zukanovic A. Antiasthmatic inhaled medications as favoring factors for increased concentration of streptococcus mutans. Mater Sociomed 2015; 27: 237-240.

6. Lindemeyer RG, Satpute NS, Katz SH. Evaluation of bronchial asthma as risk factor for early childhood caries. J Mich Dent Assoc 2012; 94: 46-49.

7. Tootla R, Toumba KJ, Duggal MS. An evaluation of the acidogenic potential of asthma inhalers. Arch Oral Biol 2004; 49: 275-283. 
8. Hyyppä TM, Koivikko A, Paunio KU. Studies on periodontal conditions in asthmatic children. Acta Odontol Scand 1979; 37: 15-20.

9. Ellepola AN, Samaranayake LP. Inhalational and topical steroids, and oral candidosis: a mini review. Oral Dis 2001; 7: 211-216.

10. World Health Organization. Oral Health Surveys Basic Methods. Geneva: WHO Press, 2013: 47-74.

11. Ismail AI, Sohn W, Tellez M, et al. The International Caries Detection and Assessment System (ICDAS): an integrated system for measuring dental caries. Community Dent Oral Epidemiol 2007; 35: 170-178.

12. Silness J, Löe H. Periodontal disease in pregnancy II. Correlation between oral hygiene and periodontal condition. Acta Odontol Scand 1964; 22: 121-135.

13. Löe $H$. The gingival index, the plaque index and the retention index systems. J Periodontol 1967; 38(Suppl): 610-616.

14. Global Initiative for Asthma (GINA). Global Strategy for Asthma Management and Prevention. 2017: 29. (Available from: http://www.ginasthma.org/).

15. Shashikiran ND, Reddy VVS, Raju PK. Effect of antiasthmatic medication on dental disease: dental caries and periodontal disease. J Indian Soc Pedod Prev Dent 2007; 25: 65-68.

16. Blumenshine SL, Vann Jr WF, Gizlice Z, Lee JY. Children's school performance: impact of general and oral health. J Public Health Dent 2008; 68: 82-87.

17. Pitts N. ICDAS-an international system for caries detection and assessment being developed to facilitate caries epidemiology, research and appropriate clinical management. Community Dent Health 2004; 21: 193-198.

18. Shulman JD, Taylor SE, Nunn ME. The association between asthma and dental caries in children and adolescents: a population-based case-control study. Caries Res 2001; 35: 240-246.

19. Meldrum AM, Thomson WM, Drummond BK, Sears MR. Is asthma a risk factor for dental caries? Findings from a cohort study. Caries Res 2001; 35: 235-239.

20. Mazzoleni S, Stellini E, Cavaleri E, Angelova Volponi A, Ferro R, Fochesato Colombani S. Dental caries in children with asthma undergoing treatment with short-acting ß2-agonists. Eur J Paediatr Dent 2008; 9: 132-138.

21. Ballikaya E, Dogan BG, Onay O, Uzamıs Tekcicek M. Oral health status of children with mouth breathing due to adenotonsillar hypertrophy. Int J Pediatr Otorhinolaryngol 2018; 113: 11-15.
22. Khalilzadeh S, Salamzadeh J, Salem F, Salem K, Vala $\mathrm{MH}$. Dental caries-associated microorganisms in asthmatic children. Tanaffos 2007; 6: 42-46.

23. Locker D. Measuring social inequality in dental health services research: individual, household and area-based measures. Community Dent Health 1993; 10: 139-150.

24. McDerra EJ, Pollard MA, Curzon ME. The dental status of asthmatic British school children. Pediatr Dent 1998; 20: 281-287.

25. Laurikainen K. Asthma and oral health: a clinical and epidemiological study. Acta Univ Tamperensis 2002. (Available from: https://trepo.tuni.fi/bitstream/ handle/10024/67473/951-44-5404-9.pdf?sequence=1)

26. Ersin NK, Guelen F, Eronat N, et al. Oral and dental manifestations of young asthmatics related to medication, severity and duration of condition. Pediatr Int 2006; 48: 549-554.

27. Mandel ID, Eriv A, Kutscher A, et al. Calcium and phosphorus levels in submaxillary saliva. Changes in cystic fibrosis and in asthma. Clin Pediatr (Phila) 1969; 8: 161-164.

28. Milano M, Lee JY, Donovan K, Chen JW. A crosssectional study of medication-related factors and caries experience in asthmatic children. Pediatr Dent 2006; 28: 415-419.

29. Lipworth BJ. Clinical pharmacology of corticosteroids in bronchial asthma. Pharmacol Ther 1993; 58: 173-209.

30. Enwonwu CO, Meeks VI, Sawiris PG. Elevated cortisol levels in whole saliva in HIV infected individuals. Eur J Oral Sci 1996; 104: 322-324.

31. Knight L, Fletcher J. Growth of Candida albicans in saliva: stimulation by glucose associated with antibiotics, corticosteroids, and diabetes mellitus. J Infect Dis 1971; 123: 371-377.

32. Samaranayake LP, MacFarlane TW. On the role of dietary carbohydrates in the pathogenesis of oral candidosis. FEMS Microbiol Lett 1985; 27: 1-5.

33. Kuna P. Longterm effects of steroid therapy. Wiad Lek 1998; 51(Suppl 1): 12-18.

34. Ogueta IC, Ramírez MP, Jiménez CO, Cifuentes MM. Geographic tongue: what a dermatologist should know. Actas Dermosifiliogr 2019; 110: 341-346.

35. McDowell JD, Kassebaum DK. Diagnosing and treating halitosis. J Am Dent Assoc 1993; 124: 55-64.

36. Motta LJ, Bachiega JC, Guedes CC, Laranja LT, Bussadori SK. Association between halitosis and mouth breathing in children. Clinics (Sao Paulo) 2011; 66: 939-942. 